\title{
GPPS-CH-2020-0086
}

\section{ENABLING THE POTENTIAL OF HYBRID ELECTRIC PROPULSION THROUGH LEAN-BURN-COMBUSTION TURBOFANS}

\author{
Stavros Vouros, Mavroudis D. Kavvalos, Smruti Sahoo and Konstantinos G. Kyprianidis \\ Future Energy Center \\ Mälardalen University, Västerås, Sweden \\ stavros.vouros@mdh.se
}

\begin{abstract}
Hybrid-electric propulsion has emerged as a promising technology to mitigate the adverse environmental impact of civil aviation. Boosting conventional gas turbines with electric power improves mission performance and operability. In this work the impact of electrification on pollutant emissions and direct operating cost of geared turbofan configurations is evaluated for an 150-passenger aircraft. A baseline two-and-a-half-shaft geared turbofan, representative of year 2035 entry-into-service technology, is employed. Parallel hybridization is implemented through coupling a battery-powered electric motor to the engine low-speed shaft. A multi-disciplinary design space exploration framework is employed comprising modelling methods for multi-point engine design, aircraft sizing, performance and pollutant emissions, mission and economic analysis. A probabilistic approach is developed considering uncertainties in the evaluation of direct operating cost. Sensitivities to electrical power system technology levels, as well as fuel price and emissions taxation are quantified at different time-frames. The benefits of lean direct injection are explored along a realistic mission scenario, demonstrating $32 \% \mathrm{NO}_{\mathrm{x}}$ savings compared to traditional rich-burn, quick-mix, lean-burn technologies. The impact of electrification on the enhancement of lean direct injection benefits is investigated. For hybrid-electric powerplants, the take-off-to-cruise turbine entry temperature ratio is $2.5 \%$ lower than the baseline, extending the corresponding $\mathrm{NO}_{\mathrm{x}}$ reductions to the level of $46 \%$. This work sheds light on the environmental and economic potential and limitations of a hybrid-electric propulsion concept towards a greener and sustainable civil aviation.
\end{abstract}

\section{INTRODUCTION}

Mitigation of the adverse environmental impact of civil aviation constitutes a major objective for manufacturers, operators and regulatory and advisory bodies (Darecki et al., 2011; Scherer, 2019). According to the 20-Year Air Passenger Forecast of the International Air Transport Association (IATA), the foreseen 3.5\% compound annual growth rate will lead to a doubling in passenger numbers compared to today's levels (IATA, 2019). Responding to this demand, a series of revolutionary propulsion system architectures has been proposed to address the challenging future requirements (Epstein, 2014; Pornet et al., 2015; Bowman et al., 2018; Sahoo et al. 2020).

Electrified propulsion has emerged as a promising concept for enhanced fuel efficiency, reduced gaseous emissions and improved operability. The potential impact of hybrid electric propulsion in regional aviation was assessed for entryinto-service (EIS) technology of 2035 (Pornet et al., 2014). Block fuel reduction of up to $20 \%$ was achieved for a hybrid electric twin-engine narrow-body aircraft, with a single electric propulsor operated in cruise. However, this figure did not account for the life-cycle energy production requirements. Similarly, weight penalties eliminated performance improvements of turbo-electric aircraft featuring a boundary layer ingesting propulsor at the fuselage aft-end (Giannakakis et al., 2019). A more conservative, boosted concept was proposed for an 150-pax aircraft with a low-speedshaft-coupled electric motor to provide power during take-off (Zhao et al., 2019). Despite operability improvements, there was no significant fuel saving with 2035 technology levels assumed for all electrical components.

NASA reported 6-14\% reductions in direct operating cost (DOC) for an 150-pax high-span hybrid electric aircraft relative to a non-electrified reference (Bradley et al., 2015). Nevertheless, these benefits were outperformed when costs associated with increased aircraft weight and complexity were included. The importance of charging the batteries with electricity from renewables to achieve concurrent reductions in $\mathrm{CO}_{2}$ emissions and $\mathrm{DOC}$ was highlighted for regional hybrid electric aircraft (Hoelzen et al., 2018). However, shifting to renewable energy ground-based plants includes 
Table 1 Overview of multi-point synthesis scheme

\begin{tabular}{ccc}
\hline & Synthesis Targets & Synthesis Variables \\
\hline Cruise & Hot-day EOR T/O & Hot-day TOC \\
\hline Pressure ratio split exp. (PRn=0.4) & NGV metal temperature for & NGV cooling flow (\% HPC flow) for \\
& $1^{\text {st }}$ and $2^{\text {nd }}$ stage HPT, and $1^{\text {st }}$ stage LPT & $1^{\text {st }}$ and $2^{\text {nd }}$ stage HPT, and $1^{\text {st }}$ stage LPT \\
Rot vel. ratio (VcoldQhot $=0.77)$ & Rotor metal temperature for $^{\text {st }}$ and $2^{\text {nd }}$ stage HPT, and $1^{\text {st }}$ stage LPT & $1^{\text {st }}$ and $2^{\text {nd }}$ stage HPT, and $1^{\text {st }}$ stage LPT \\
Specific thrust (SFN=91) & & Bypass ratio and Fan tip pressure ratio \\
Overall pressure ratio $(\mathrm{OPR}=55)$ & & IPC pressure ratio and HPC pressure ratio \\
\hline
\end{tabular}

complex considerations (Epstein, 2019): airline operations are not evenly distributed around the globe and considerable transmission losses would occur unless renewable sources were installed around airports. Nevertheless, the area requirements and cost of infrastructure for installation of renewables near airports would be excessive.

The potential impacts of electrification on pollutant emissions are frequently outperformed by the associated weight penalties. Apart from hybridization, low-emissions combustor technologies have been proposed to directly mitigate the environmental impact at source. Lean direct injection (LDI) can achieve reduced peak flame temperatures at medium to high power compared to traditional rich-burn quick-quench lean-burn (RQL) combustors (Dewanji et al., 2015). However, LDI is more sensitive to combustion instabilities due to the challenging uniformity requirements in the fuel-air mixture before the reaction (Liu et al., 2017). This renders LDI performance largely dependent on the primary zone flame temperature ratio between take-off and cruise (Kyprianidis et al., 2017).

The design of the primary zone of LDI combustors in terms of reducing carbon monoxide (CO) and nitrogen oxide $\left(\mathrm{NO}_{\mathrm{x}}\right)$ emissions, is governed by the trade-off between take-off and cruise emissions. These two operating conditions impose conflicting combustor design objectives, due to the diversity in the associated engine performance parameters which govern the primary zone flame temperature. Reduction of the lapse rate between take-off and cruise conditions was studied for intercooled recuperated configurations, featuring variable geometry low-pressure turbines (Kyprianidis $e t$ al., 2011). It was shown that a $60 \mathrm{~K}$ increase in the intercooled recuperated core temperature during cruise yielded $10 \%$ improvements in the landing and take-off (LTO) $\mathrm{NO}_{\mathrm{x}}$ margin relative to ICAO certification limits, due to the primary zone design balance between take-off and cruise conditions. Alternative methods to achieve reduced lapse rates involve de-rated thrust take-off procedures in excess runway length conditions (Takahashi, 2015).

The scope of this work is to "unlock" the potential of electrification with respect to environmental impact and economic viability of medium-large aircraft gas turbine engines featuring LDI combustors. A geared turbofan configuration is employed, boosted by a battery-powered electric motor, coupled with the low-speed shaft of the gas turbine engine. The motor provides electric power during take-off, climb-out and climb to reduce the take-off-to-cruise turbine entry temperature (TET), therefore enhancing the effectiveness of LDI combustion. The battery system is fully recharged during descent yielding minimal ground infrastructure requirements and advancing the technology readiness level (TRL) of the proposed concept.

\section{METHODOLOGY}

\section{Gas turbine engine simulation environment}

The multi-disciplinary conceptual design and performance simulation framework EVA (Kyprianidis et al., 2008; Kyprianidis, 2017) is employed for the techno-economic and environmental gas turbine assessment undertaken in this work. EVA comprises a series of state-of-the-art individual modelling methods for multi-point gas turbine engine design, aircraft-engine performance, mission simulation and economic analysis (Kyprianidis, 2019). The individual modules have been extensively described and validated (Kyprianidis, 2017) therefore further elaboration will be limited.

Combustor pollutant emissions are modelled based on validated correlations derived from experimental data (Kyprianidis et al., 2017). RQL combustor $\mathrm{NO}_{\mathrm{x}}$ emissions index is expressed as function of combustor entry temperature and pressure, ambient humidity and combustor outlet-inlet total temperature difference. The LDI combustor $\mathrm{NO}_{x}$

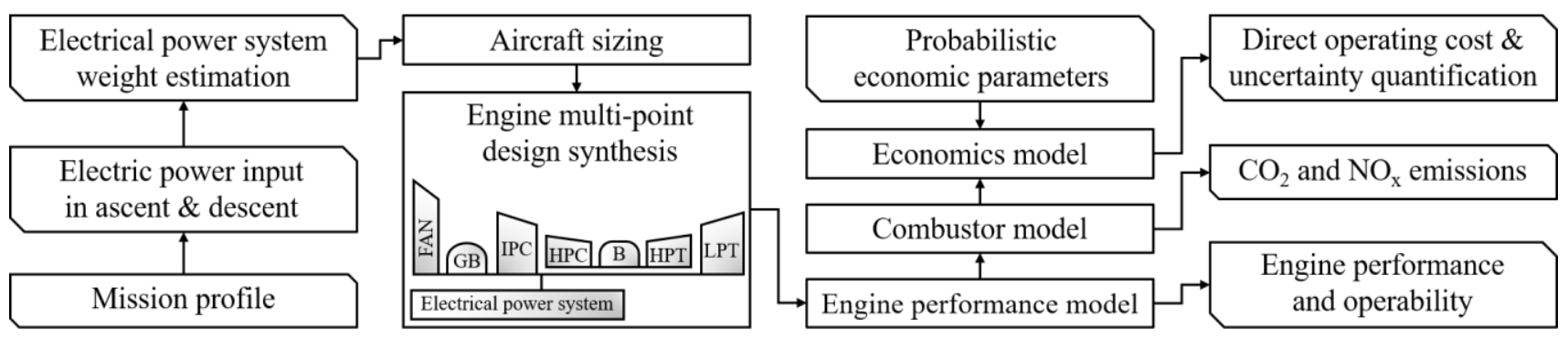

Figure 1 Design space exploration methodology 

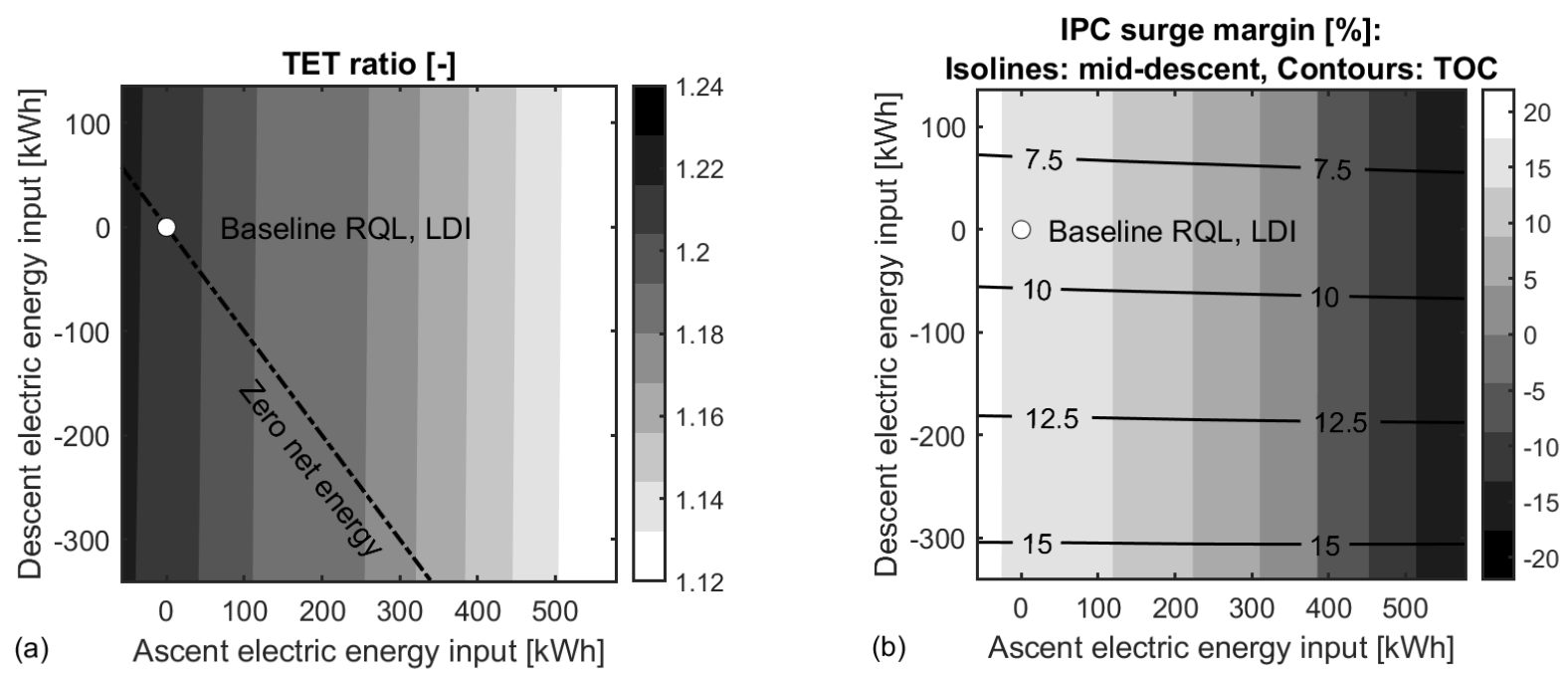

Figure 2 Impact of electrification on gas turbine performance as function of electric energy input to the low-speed shaft during ascent and descent; (a) take-off-to-cruise TET ratio, (b) IPC surge margins in descent and top-of-climb

correlation is a function of combustor flame temperature and inlet total pressure. A pressure correction exponent factor of 0.5 is employed in the LDI combustor model, which is considered as conservative design choice (Kyprianidis et al., 2017). The complete set of semi-empirical model parameters for RQL and LDI combustors is provided in the same reference, therefore restatement would be redundant.

A rubberized wing aircraft model is utilized for sizing the aircraft at fixed wing loading based on the designated mission range and propulsion system design. The basic principles of aircraft weight estimation, sizing, aerodynamics and performance are discussed in the relevant literature (Roskam, 1985; ESDU, 1997; Jenkinson et al., 1999; Torenbeek, 2013). A multi-point engine design and performance simulation scheme performs a thermodynamic cycle matching at multiple operating points ((Kyprianidis, 2010). A set of independent parameters (synthesis variables) is solved at designated reference conditions to satisfy an equally-sized set of performance targets (synthesis targets) at specific operating conditions (Sielemann et al., 2020). Mission simulation is accomplished through an iterative method with total mission fuel convergence termination criterion (Kyprianidis, 2017).

\section{Hybrid-electric configuration}

A non-electrified, two-and-a-half-shaft geared turbofan engine configuration with 2035 EIS year technology assumptions (Zhao et al., 2019a; Sahoo et al., 2019) is employed as baseline engine for the purposes of this study. As previously mentioned, a multi-point synthesis method is used for gas turbine engine design and steady-state performance, where synthesis variables at hot-day top-of-climb (TOC) are varied to achieve the synthesis targets at hot-day end-ofrunway take-off (EOR T/O) and Cruise operating conditions. Table 1 outlines the multi-point matching scheme selected for this engine architecture. Engine design optimization for minimum block mission fuel consumption has been undertaken for four key design synthesis targets, namely cruise overall pressure ratio (OPR), specific thrust (SFN), ideal jet velocity ratio (VcoldQhot) and pressure ratio split exponent (PRn) at cruise (Zhao et al., 2019a). Table 1 provides the optimized values of main design parameters for the baseline configuration.

Single-aisle commercial airliners represent about $36 \%$ of the total aviation fuel consumption (Epstein, 2019), therefore an 150-pax aircraft is employed to illustrate the potential impact of the present study. A benchmark flight profile with realistic mission phases is deployed (Zhao et al., 2019b). A range of $973 \mathrm{~km}$ is selected for the business case considered in this work, representative of typical short-medium range commercial aircraft operations.

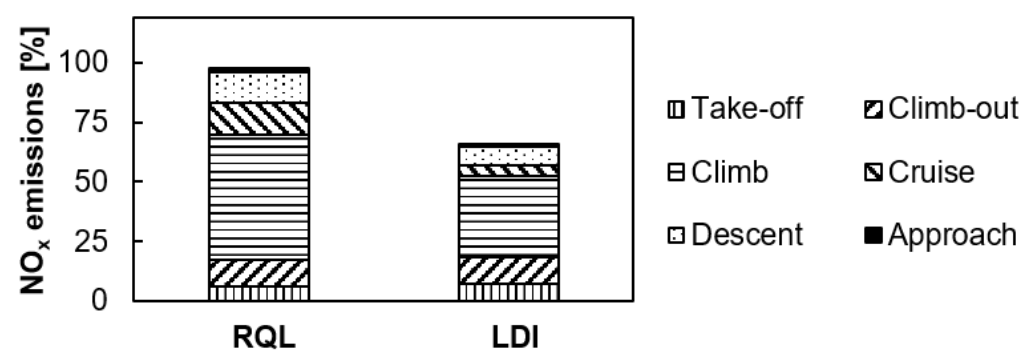

Figure 3 Mission $\mathrm{NO}_{x}$ emissions break-down for RQL and LDI combustors (normalized for RQL) 

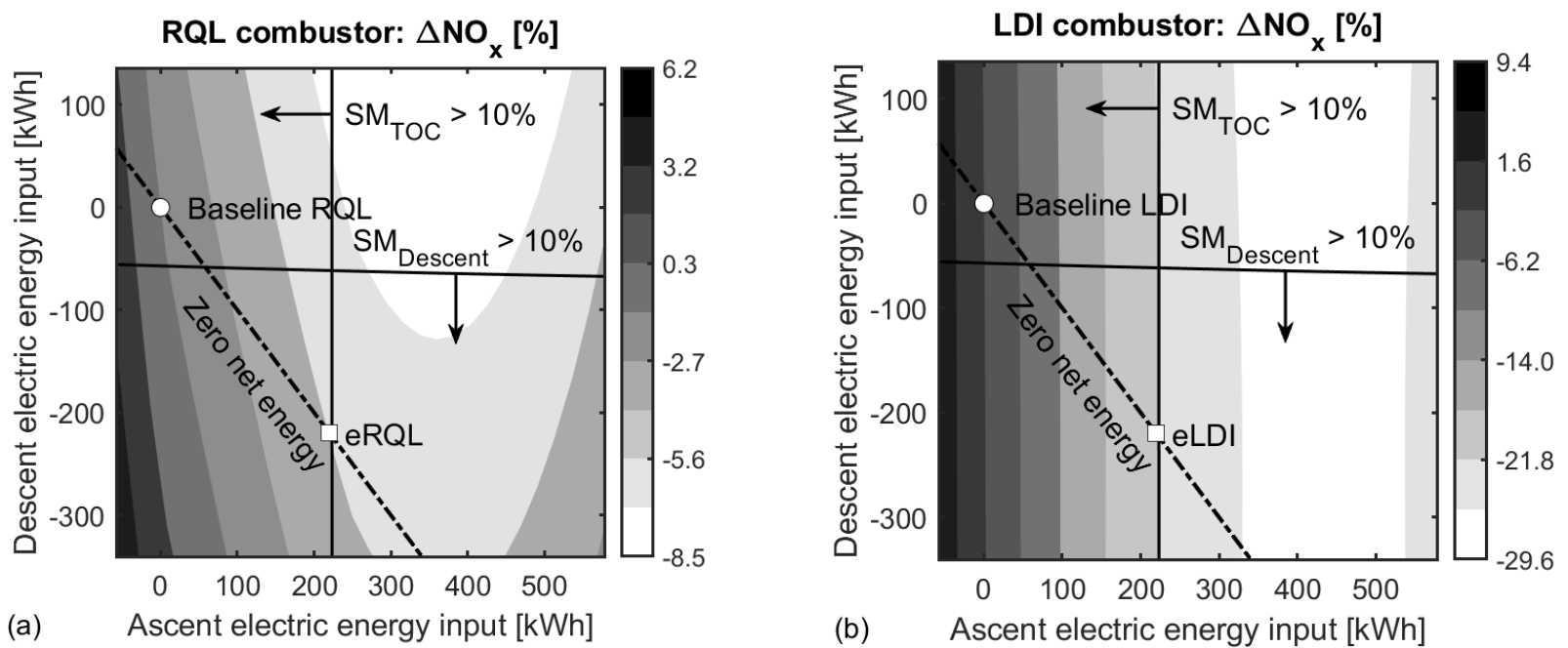

\section{Figure 4 Impact of electrification on $\mathrm{NO}_{\mathrm{x}}$ emissions as function of electric energy input to the low- speed shaft during ascent and descent; (a) RQL combustor, (b) LDI combustor}

The electrified variant of this engine is implemented through coupling of a battery-powered electric motor with the low-speed shaft of the gas turbine. The electric motor provides electric power to the low-speed shaft during the ascending phase of the mission, which comprises the take-off, climb-out and climb stages. The aim of boosting is to off-load the low-pressure system during high-power conditions, therefore reducing the take-off-to-cruise TET ratio and consequently, $\mathrm{CO}_{2}$ and $\mathrm{NO}_{\mathrm{x}}$ emissions. During descent, an appropriate amount of power is extracted from the low-speed shaft to recharge the batteries. The purpose of re-charging is to reduce compressor handling bleeds, but also to minimize new ground infrastructure requirements and accelerate the advancement of TRL of this concept.

\section{Design space exploration framework}

A multi-disciplinary design space exploration (DSE) strategy is implemented to investigate the impact of electrification on the environmental and economic potential of propulsion systems featuring conventional and lean-burn combustion technologies. The design variables considered in this investigation are the electric power input or extraction during the ascending and during the descending phase of the mission. The effects of simultaneous variation of these values is quantified with respect to total mission $\mathrm{CO}_{2}$ and $\mathrm{NO}_{\mathrm{x}}$ emissions, and DOC. A Monte Carlo simulation scheme is established to quantify the impact of uncertainty in key economic parameters on the calculation of DOC. The individual weight of the electrical power system components is approximated based on performance correlations and technology factors, therefore accounting for the primary effects of electrification on the overall aircraft weight. An overview of the design space exploration algorithm is illustrated in Fig. 1.

The output of DSE is the overall system environmental and economic sensitivity to combined variations of the ascent and descent electrification scenarios. Optimized hybrid electric designs are identified achieving minimum $\mathrm{CO}_{2}$ and $\mathrm{NO}_{\mathrm{x}}$ emissions, whilst satisfying a set of surge-margin and net-electric-energy constraints at mission level.

\section{RESULTS AND DISCUSSION}

\section{Gas turbine performance and operability}

The impact of combined variation of ascending and descending electric power input or extraction on the ratio of TET between take-off and cruise is illustrated in Fig. 2 (a). Each and every point of the DSE representation corresponds to a dedicated gas turbine multi-point design synthesis, electrical power system weight estimation, aircraft sizing and full mission simulation. The analysis has been undertaken at energy level to illustrate the relative requirements between ascent and descent. Positive sign represents electric power input, whilst negative corresponds to power extraction. The baseline, non-electrified, turbofan configuration will serve as reference point for the analysis to follow. Furthermore, the line of zero net electric energy between ascent and descent describes the locus of electrified propulsion designs beyond which no ground charging or replacement of batteries is required. Overall, the TET ratio between take-off and cruise is primarily governed by variations of the ascent electric energy input. Boosting the low speed shaft in high power conditions leads to lower OPR and HPC delivery temperatures, hence reduced TET during ascent (Walsh et al., 2004). The baseline TET ratio of 1.22 between take-off and cruise can drop down to 1.12 for relatively high degrees of ascending power hybridization. 

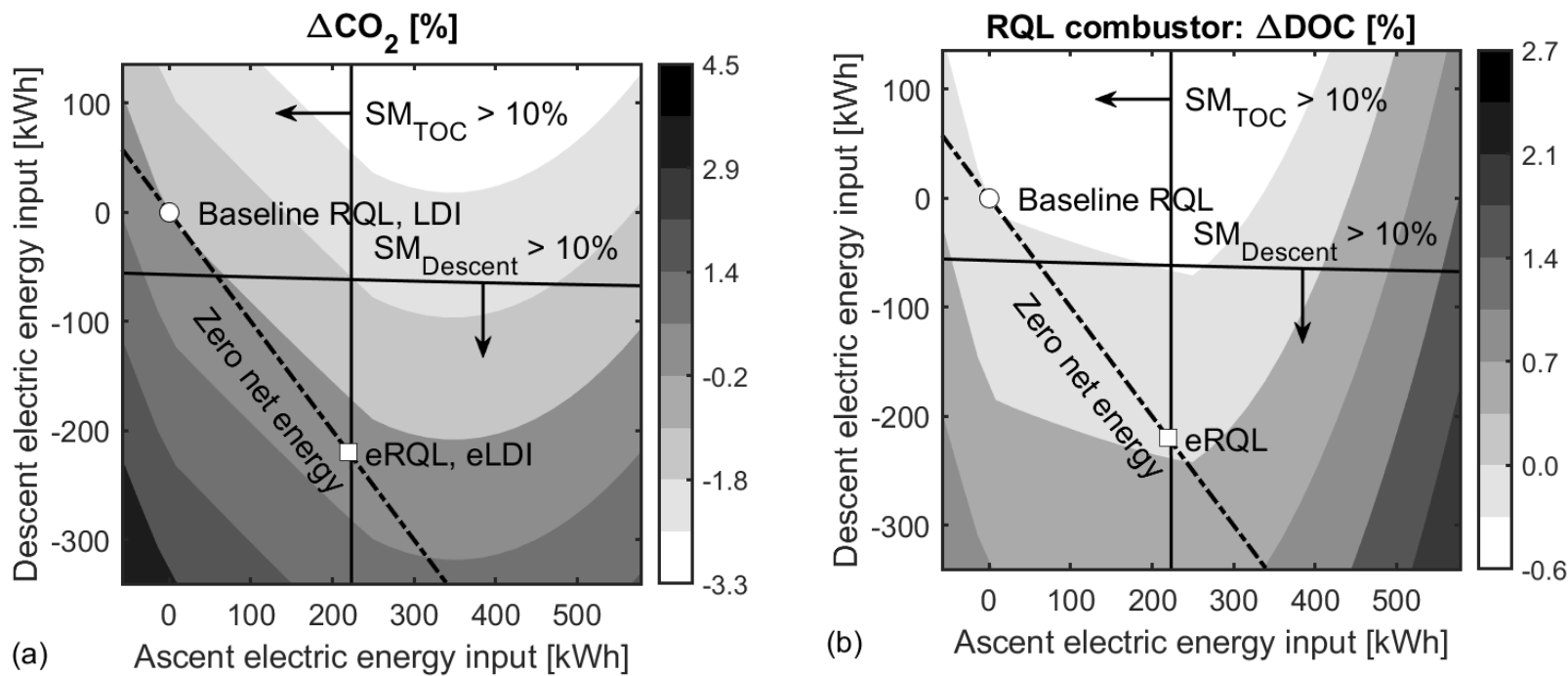

\section{Figure 5 Impact of electrification on $\mathrm{CO}_{2}$ emissions and economics as function of electric energy input to the low-speed shaft during ascent and descent; (a) $\mathrm{CO}_{2}$, (b) direct operating cost}

Electric power input or extraction has impact on the operability of gas turbine components. Operability is represented by surge margins, defined at constant rotational speed line, as the pressure ratio (PR) difference between the surge line and the off-design point divided by the surge line PR (Kavvalos et al., 2019). For the specific concept under investigation, it has been shown that at the top of climb (TOC), it is the surge margin of the intermediate pressure compressor (IPC) which is more sensitive to dropping below acceptable thresholds, since boosting leads to a rise in IPC PR and reduction in mass flow (Zhao, 2019a). The same component represents the "bottleneck" in mid-descent. Fig. 2 (b) shows the impact of electrification on the operability of the most critical gas turbine component during ascent and descent. Excessively high boosting during ascent can lead to negative surge margins, whilst power extraction from the low-speed shaft during descent improves operability through reducing compressor handling bleeds (Kurzke et al., 2018). For the purposes of this investigation, a $10 \%$ surge margin will be considered as lowest operability threshold, therefore defining the constraints for the search of optimal hybrid electric configurations across the designated design space.

\section{NOx emissions}

Figure 3 presents the break-down of $\mathrm{NO}_{\mathrm{x}}$ emissions along the benchmark mission profile for a gas turbine engine featuring RQL and LDI combustor. No electrification strategy is considered in this comparison. The vertical axis is normalized based on the total $\mathrm{NO}_{\mathrm{x}}$ emitted for the RQL case. It is shown that total $\mathrm{NO}_{\mathrm{x}}$ emissions for the LDI combustor are $32 \%$ lower compared to the RQL, in accordance with the findings quoted in previous studies (Forum-AE, 2015). For the RQL combustor, $70 \%$ of the total mission $\mathrm{NO}_{\mathrm{x}}$ is emitted during the ascending phase of the mission which comprises take-off, climb-out and climb. The same figure for the LDI combustor reaches $78 \%$, which highlights the importance of reducing take-off-to-cruise TET ratio in this configuration through boosting. It is worth noting that the duration of the descending phase is about 2.4 times larger than the ascending one, which allows for a lower degree of power hybridization during re-charging, therefore keeping IPC descent surge margins at acceptable levels.

Figure 4 (a) illustrates the effects of electrification on total mission $\mathrm{NO}_{\mathrm{x}}$ for RQL combustors. The results are normalized based on the total emissions of the non-electrified baseline configuration. Electrified designs laying above and right of the zero-net-energy line offer flight $\mathrm{NO}_{\mathrm{x}}$ deltas of up to $-8.5 \%$, however without resolving the additional emissions associated with ground battery charging. The aim of this study is to propose a hybrid electric design with minimal ground charging requirements, therefore, the search space for the optimal configuration reduces to the locus of zero net electric energy designs. Furthermore, the 10\% surge margins are superimposed, effectively defining the design constraints for this configuration. Consequently, the optimal electrified design requires $220 \mathrm{kWh}$ of electric energy input during ascent, which is entirely recovered during descent. This is translated to a $9.5 \%$ degree of power hybridization during ascent and $-6.2 \%$ during descent, based on the associated duration of each mission phase.

Table 2 Direct operating cost uncertainty analysis (95\% confidence intervals) at different time horizons

\begin{tabular}{cccccc}
\hline Time horizon & Fuel price [USD/gal] & Exchange rate [-] & Interest rate [\%] & Inflation rate [\%] & $\Delta$ DOC [\%] \\
\hline 1 year & $1.81 \pm 0.37$ & $0.90 \pm 0.02$ & $1.03 \pm 0.70 \%$ & $1.48 \pm 0.39 \%$ & $0.4 \pm 2.5 \%$ \\
5 years & $1.65 \pm 0.61$ & $0.89 \pm 0.06$ & $1.14 \pm 0.54 \%$ & $1.18 \pm 1.48 \%$ & $0.4 \pm 3.6 \%$ \\
10 years & $2.20 \pm 1.33$ & $0.82 \pm 0.07$ & $2.29 \pm 2.49 \%$ & $1.51 \pm 1.96 \%$ & $0.4 \pm 8.4 \%$ \\
\hline
\end{tabular}


$\mathrm{NO}_{\mathrm{x}}$ is primarily governed by variation in electric energy input during ascent, due to the impact of low-speed-shaft off-loading on TET. Nevertheless, power extraction during descent has also an effect on total $\mathrm{NO}_{\mathrm{x}}$. For the defined optimization constraints, the optimal electrified RQL configuration (eRQL) demonstrates $-4 \% \mathrm{NO}_{\mathrm{x}}$ deltas relative to the baseline RQL. The associated TET ratio between take-off and cruise is 1.18 , which is $2.5 \%$ lower than the baseline. For a combination of $14.7 \%$ ascent and $6.2 \%$ descent hybridization, a total $\mathrm{NO}_{\mathrm{x}}$ delta of $-7.7 \%$ occurs; albeit at a cost of ground emissions and infrastructure requirements for battery re-charging or replacement. It is worth noting that if electrical power system weight had been neglected, $\mathrm{NO}_{\mathrm{x}}$ deltas between $\mathrm{RQL}$ and baseline RQL would be $-6.2 \%$, which depicts the importance of including the first-order effects of electrification on aircraft weight estimation (Perullo et al., 2016).

Figure 4 (b) presents the corresponding response for LDI combustors. It is observed that total mission $\mathrm{NO}_{\mathrm{x}}$ is less sensitive to power input or extraction in low-power descent conditions. The benefits of electrification present considerably higher margins compared to the corresponding RQL figures. Specifically, a $\mathrm{NO}_{\mathrm{x}}$ delta of $-19.8 \%$ is calculated for the optimal hybrid-electric engine with LDI combustor (eLDI) relative to the non-electrified LDI variant. As discussed in Fig. 3, LDI technology alone results to $\mathrm{NO}_{\mathrm{x}}$ reductions in the order of $32 \%$, yielding a cumulative $\mathrm{NO}_{\mathrm{x}}$ saving in the order of $46 \%$ for the eLDI configuration, relative to the non-electrified RQL. It is therefore demonstrated that electrification presents better potential for application on engines featuring LDI combustors, roughly promising a halving of total $\mathrm{NO}_{\mathrm{x}}$ emissions with respect to their non-electrified RQL counterparts.

\section{$\mathrm{CO}_{2}$ emissions, economics and uncertainty}

The effects of low-speed shaft power input or extraction during ascent and descent are essentially reflected on the total mission $\mathrm{CO}_{2}$ emissions, as shown in Fig. 5 (a). It is noted that the gas turbine performance model does not account for variations in the combustor configuration, therefore the present $\mathrm{CO}_{2}$ analysis represents both RQL and LDI variants. The $\mathrm{CO}_{2}$ delta corresponding to the NOx-optimized electrification strategy is $0.5 \%$ relative to the baseline engine. It is noted that a separate optimization for $\mathrm{CO}_{2}$ along the zero-net-energy line would yield a $0.1 \%$ delta. The best attainable $\mathrm{CO}_{2}$ delta in flight is $-3.3 \%$, however it is expected that this number would be penalized by $\mathrm{CO}_{2}$ emissions associated with ground battery charging or replacement. The previous considerations depict that there is significant $\mathrm{CO}_{2}$ benefit expected from the optimization of this configuration. Nevertheless, it is the potential reduction of $\mathrm{NO}_{\mathrm{x}}$ emissions that shall be the motive for optimizing this concept, whilst keeping associated $\mathrm{CO}_{2}$ penalties at a minimum.

Variations in fuel consumption and pollutant emissions due to hybrid electric designs are essentially reflected on aircraft DOC. Estimation of DOC requires input from many market-related parameters which fluctuate with time. For this reason, a deterministic cost estimation is avoided and a probabilistic approach for the evaluation of DOC is developed. Specifically, a Monte Carlo simulation scheme is established to account for uncertainties in key economic parameters, namely fuel price, exchange rate, interest rate and inflation rate. The mean value and associated uncertainty for these parameters is calculated based on one-year-horizon historical data. The statistical analysis undertaken for the historical data suggest Gaussian distributions to be assigned to all uncertain input parameters.

The distribution of the mean value of DOC relative deltas for the engine equipped with RQL combustor is represented in Fig. 5 (b). It is noted that each and every point of this illustration represents a dedicated Monte Carlo simulation with sample size of 1000 points, which was found to be sufficient for the convergence of the first four statistical moments of DOC. It is observed that DOC follows similar patterns as $\mathrm{CO}_{2}$, hence fuel is the parameter which governs the response of DOC for this configuration. The corresponding distribution for the LDI configuration is almost identical, hence it was deemed unnecessary to include this illustration. For both RQL and LDI hybrid electric variants, mean DOC delta varies between $-0.6 \%$ and $2.7 \%$ across the design space, whilst the optimal electrified designs present a delta of roughly $0.4 \%$. It is concluded that the investigated hybrid electric concept does not offer significant DOC reductions, nor brings increased running costs.

The associated DOC variability is uniformly distributed throughout the design space, presenting a $\pm 2.5 \%$ uncertainty within $95 \%$ confidence intervals. The quoted mean DOC deltas and associated uncertainty are based on one-year time windows. However, different time horizons shall be considered for the evaluation of economic viability of the proposed design. Table 2 presents the quantification of uncertainty within one-, five- and ten-year horizons, all referring to the optimized electrified design of the RQL variant within $95 \%$ confidence intervals. It is shown that the mean value of DOC

Table 3 Specification of electrical power system components at different time-frames

\begin{tabular}{llccc}
\hline \multirow{2}{*}{ Component } & \multirow{2}{*}{ Specification } & $\mathbf{3}$ Time-frame \\
\cline { 3 - 5 } Battery & Specific energy [Wh/kg] & 300 & $\mathbf{2 0 3 5}$ & $\mathbf{2 0 5 0}$ \\
& Specific power [W/kg] & 700 & 1,230 & 2,000 \\
\multirow{3}{*}{ Motor/Generator } & 0.95 & 0.98 & 2,000 \\
& Efficiency [-] & 2,500 & 15,000 & 28,000 \\
Specific power [W/kg] & 0.92 & 0.96 & 0.99 \\
& Efficiency [-] & 1,600 & 20,000 & 26,000 \\
& Specific power [W/kg] & 0.95 & 0.97 & 0.99 \\
\hline
\end{tabular}



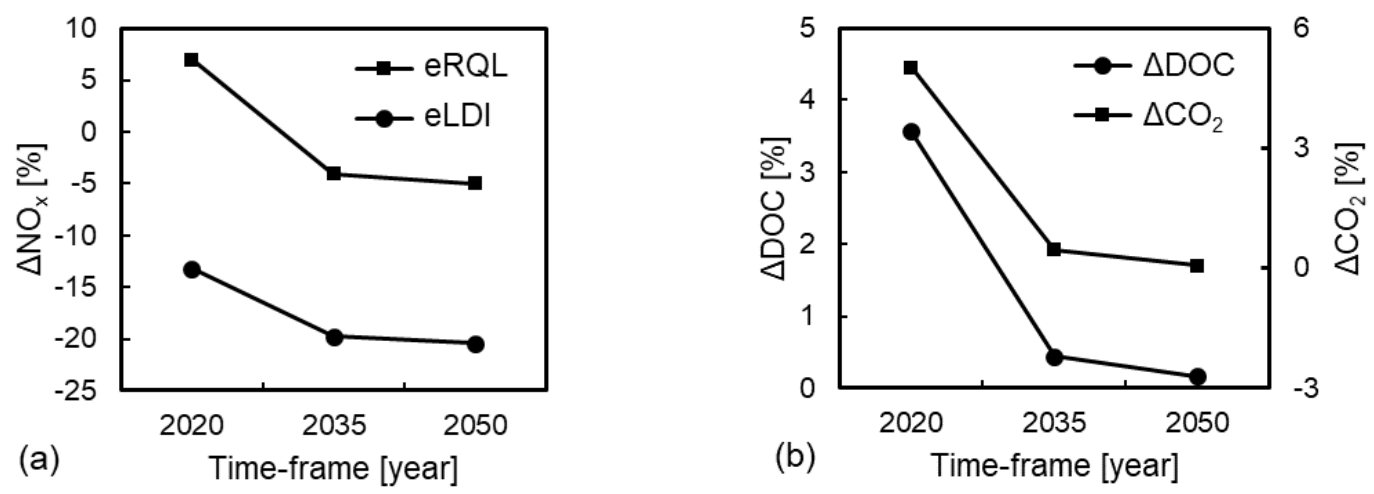

Figure 6 Impact of electrical system technology levels on the environmental and economic potential of hybrid electric turbofans

delta is not significantly affected; however, the associated uncertainty can reach up to $\pm 8.4 \%$ in a ten-year horizon. Almost identical numbers where accrued for the eLDI configuration which depicts the relatively low impact of the present $\mathrm{NO}_{\mathrm{x}}$ taxation rate on DOC.

A variance-based Sobol sensitivity analysis (Sobol, 1993; Homma et al., 1996) is carried out to quantify the relative contribution of each uncertain input parameter to the overall system uncertainty. The calculated Sobol global sensitivity indices are uniformly distributed across the design space, therefore only the range of variation for each index is provided. Specifically, fuel price variations contribute $69-72 \%$ to the overall uncertainty, whilst interest rate is responsible for $25-$ $29 \%$. Uncertainties in the exchange and inflation rates get only $2-3 \%$ and $0-1 \%$ of the total share, respectively. The above numbers reveal which are the economic parameters that should be primarily examined in the evaluation of new concepts.

\section{Impact of electrical power system technology}

Sizing of the electrical power system is crucial for the realistic estimation of environmental and economic deltas for new concepts (Wroblewski et al., 2019). In this work, the first-order effects of electrification on aircraft weight are captured via utilizing technology factors for the individual components (Pornet et al., 2014; Bradley et al., 2015; Gnadt et al., 2019; Zhao et al., 2019a). 2035 EIS technology levels have been assumed in the results presented in the previous sections. However, it is deemed necessary to investigate the impact of technological assumptions on the anticipated deltas. Therefore, two different time-frames are also considered, 2020 and 2050. Table 3 summarizes the technological assumptions considered for each component of the electrical power system.

Figure 6 (a) presents the impact of electrical system technology levels on $\mathrm{NO}_{\mathrm{x}}$ deltas for optimized RQL and LDI hybrid electric configurations. For the RQL configuration, electrification benefits are outperformed by weight penalties imposed due to the relatively low battery specific energy in the 2020 time-frame, yielding a $7 \%$ increase in $\mathrm{NO}_{\mathrm{x}}$ emissions relative to their non-electrified counterparts. Similarly, as shown in Fig. 6 (b), DOC and $\mathrm{CO}_{2}$ deltas are in the order of $3.5 \%$ and $5 \%$, respectively, in 2020. In the 2035 and 2050 time-frames, electrified RQL configurations achieve $4 \%$ and $5 \% \mathrm{NO}_{\mathrm{x}}$ reductions, whilst the corresponding figures for LDI are $19 \%$ and $20 \% . \mathrm{CO}_{2}$ and DOC range between $2 \%$ and $0 \%$ for both combustion technologies, in 2035 and 2050. Overall, for the 2035+ time-frame, it is concluded that due to the relatively low degrees of power hybridization, the impact of electrical power system weight is small compared to more aggressively electrified configurations. This increases the level of trust to the proposed hybrid electric concept, which demonstrates adequate robustness for consideration in both mid- and long-term electrification solutions. It is noted that the accrued deltas are subject to the technological assumptions regarding electrical components and combustor performance. Nevertheless, this study aims to showcase the associated sensitivity magnitudes and provide insight about the technological maturity levels required to enable the utilization of these concepts.

\section{Impact of fuel price and $\mathrm{NO}_{\mathrm{x}}$ taxation}

The Sobol-based sensitivity analysis demonstrated that fuel price is the governing source of uncertainty in the probabilistic calculation of DOC. Fuel price does frequently exert extreme variations due to socio-geo-political events

Table 4 Impact of fuel price and $\mathrm{NO}_{\mathrm{x}}$ tax on direct operating cost

\begin{tabular}{|c|c|c|c|}
\hline \multicolumn{2}{|c|}{$\Delta \mathrm{DOC}[\%]$} & Fuel price $-80 \%$ & Fuel price $+\mathbf{8 0 \%}$ \\
\hline \multirow{2}{*}{$\mathrm{NO}_{\mathrm{x}} \operatorname{tax}-\mathbf{5 0 \%}$} & eRQL & $0.5 \pm 1.5 \%$ & $0.4 \pm 3.7 \%$ \\
\hline & eLDI & $0.3 \pm 1.5 \%$ & $0.3 \pm 3.7 \%$ \\
\hline \multirow{2}{*}{$\mathrm{NO}_{\mathrm{x}} \operatorname{tax}+\mathbf{5 0 0 \%}$} & eRQL & $0.1 \pm 1.3 \%$ & $0.1 \pm 3.3 \%$ \\
\hline & eLDI & $-0.6 \pm 1.3 \%$ & $-0.5 \pm 3.3 \%$ \\
\hline
\end{tabular}


and circumstances. Furthermore, $\mathrm{NO}_{\mathrm{x}}$ taxation varies considerably around the globe, whilst much stricter future policies are anticipated in the context of suppressing LTO emissions. Therefore, the sensitivity of accrued DOC is explored in extreme variations of fuel price and $\mathrm{NO}_{\mathrm{x}}$ tax. Fuel price is varied between $-80 \%$ and $80 \%$ and $\mathrm{NO}_{\mathrm{x}}$ tax between $-50 \%$ and $500 \%$. Table 4 summarizes the mean DOC deltas and associated uncertainties for both eRQL and eLDI variants, relative to their non-electrified counterparts. Mean values and corresponding uncertainties for the input economic parameters are based on one-year-horizon historical data.

It is observed that for low fuel prices DOC uncertainty is around 1.3-1.5\%, whilst high fuel prices yield uncertainties between 3.3-3.7\%. On the other hand, high $\mathrm{NO}_{\mathrm{x}}$ tax reveals negative DOC deltas for the eLDI configuration. which highlights the potential economic benefits of the proposed technology, if stricter $\mathrm{NO}_{\mathrm{x}}$ taxation is applied. Overall, fuel price governs the uncertainty in DOC estimation, whilst a potentially higher future $\mathrm{NO}_{\mathrm{x}}$ tax would render the electrified LDI engine more economically attractive compared to traditional or electrified RQL configurations.

\section{CONCLUSIONS}

A systematic design space exploration has been presented for the quantification of environmental and technoeconomic potential of a hybrid electric turbofan configuration featuring lean direct injection combustor technology. It has been shown that boosting the low-speed shaft during the ascending phase of a benchmark mission leads to reduced takeoff-to-cruise TET ratio which yields reduced $\mathrm{NO}_{\mathrm{x}}$ emissions. A battery-recharging strategy during descent has been introduced, rendering the aircraft independent of ground charging or additional infrastructure, therefore advancing the TRL levels of the proposed concept.

For traditional RQL combustor technologies, electrification leads to $4 \% \mathrm{NO}_{\mathrm{x}}$ reductions relative to the associated non-electrified variant. The corresponding improvement margins for electrified turbofans with LDI combustors rise to $19.8 \%$ relative to non-electrified LDI, showcasing the improved potential of this technology compared with RQL. Overall, optimized hybrid electric configurations with LDI combustor promise a $47 \%$ reduction relative to non-electrified RQL configurations, primarily attributed to the reduced lapse between take-off and cruise primary zone flame temperature which allows more balanced combustor designs. These benefits come at a $0.4 \%$ penalty in $\mathrm{CO}_{2}$ emissions and direct operating cost, demonstrating that added weight due to electrification outperforms theoretical fuel benefits.

Potentially stricter $\mathrm{NO}_{\mathrm{x}}$ taxation policies are beneficial for LDI combustors, yielding the technology more economically viable compared to RQL. Finally, the impact of electrical power system technology on the anticipated deltas is relatively small in the 2035+ time-frame due to the low degrees of power hybridization required for the implementation of the proposed concept. This increases the level of confidence on this strategy, rendering the concept a robust technological solution for the mid- and long-term. Future studies can be focused on expanding the findings of this work, through alternative electrification architectures, or even non-electrified configurations, capable of reducing the lapse rate between take-off and cruise and mitigating the environmental impacts of future aviation.

\section{ACKNOWLEDGMENTS}

This work has received funding support from Clean Sky 2 Joint Undertaking under European Union's Horizon 2020 research and innovation programs HECARRUS in grant agreement number 865089.

\section{REFERENCES}

Bowman, C.L., Felder, J.L. and Marien, T.V., 2018, July. Turbo-and Hybrid-electrified aircraft propulsion concepts for commercial transport. In 2018 AIAA/IEEE Electric Aircraft Technologies Symposium (EATS) (pp. 1-8). IEEE.

Bradley, M.K. and Droney, C.K., 2015. Subsonic ultra green aircraft research: Phase 2. Volume 2; Hybrid electric design exploration.

Darecki, M., Edelstenne, C., Enders, T., Fernandez, E., Hartman, P., Herteman, J.P., Kerkloh, M., King, I., Ky, P., Mathieu, M. and Orsi, G., 2011. Flightpath 2050 Europe's vision for aviation. Off. Eur.

Dewanji, D. and Rao, A.G., 2015. Spray combustion modeling in lean direct injection combustors, Part I: Singleelement LDI. Combustion Science and Technology, 187(4), pp.537-557.

Epstein, A.H. and O'Flarity, S.M., 2019. Considerations for Reducing Aviation's $\mathrm{CO}_{2}$ with Aircraft Electric Propulsion. Journal of Propulsion and Power, 35(3), pp.572-582.

Epstein, A.H., 2014. Aeropropulsion for commercial aviation in the twenty-first century and research directions needed. AIAA journal, 52(5), pp.901-911.

ESDU, 1997. Estimation of airframe drag by summation of components: Principles and examples. ESDU-97016

FORUM-AE, 2015. FP7 Coordination Action - GA 605506

Giannakakis, P., Maldonado, Y.B., Tantot, N., Frantz, C. and Belleville, M., 2019. Fuel burn evaluation of a turboelectric propulsive fuselage aircraft. In AIAA Propulsion and Energy 2019 Forum (p. 4181).

Gnadt, A.R., Speth, R.L., Sabnis, J.S. and Barrett, S.R., 2019. Technical and environmental assessment of all-electric 180-passenger commercial aircraft. Progress in Aerospace Sciences, 105, pp.1-30. 
Hoelzen, J., Liu, Y., Bensmann, B., Winnefeld, C., Elham, A., Friedrichs, J. and Hanke-Rauschenbach, R., 2018. Conceptual design of operation strategies for hybrid electric aircraft. Energies, 11(1), p.217.

Homma, T. and Saltelli, A., 1996. Importance measures in global sensitivity analysis of nonlinear models. Reliability Engineering \& System Safety, 52(1), pp.1-17.

IATA, 2019. Aircraft Technology Roadmap to 2050.

Jenkinson, L.R., Simpkin, P., Rhodes, D., Jenkison, L.R. and Royce, R., 1999. Civil jet aircraft design (Vol. 338). London: Arnold.

Kavvalos, M.D., Xin, Z., Schnell, R., Aslanidou, I., Kalfas, A. and Kyprianidis, K., 2019. A Modelling Approach of Variable Geometry for Low Pressure Ratio Fans. In International Symposium on Air Breathing Engines, ISABE 2019, Canberra, Australia, 23-27 September 2019 Paper No. ISABE-2019-24382.

Kurzke, J. and Halliwell, I., 2018. Propulsion and Power: An Exploration of Gas Turbine Performance Modeling. Springer.

Kyprianidis, K., 2017. An Approach to Multi-Disciplinary Aero Engine Conceptual Design. In International Symposium on Air Breathing Engines, ISABE 2017, Paper No. ISABE-2017-22661.

Kyprianidis, K.G. and Dahlquist, E., 2017. On the trade-off between aviation $\mathrm{NO}_{\mathrm{x}}$ and energy efficiency. Applied Energy, 185, pp.1506-1516.

Kyprianidis, K.G., 2010. Multi-disciplinary conceptual design of future jet engine systems. Doctoral Dissertation, Cranfield University, UK.

Kyprianidis, K.G., Grönstedt, T., Ogaji, S.O., Pilidis, P. and Singh, R., 2011. Assessment of future aero-engine designs with intercooled and intercooled recuperated cores. Journal of Engineering for Gas Turbines and Power, 133(1).

Kyprianidis, K.G., 2019. On Gas Turbine Conceptual Design, Doctoral Dissertation, Cranfield University, UK.

Kyprianidis, K.G., Colmenares Quintero, R.F., Pascovici, D.S., Ogaji, S.O., Pilidis, P. and Kalfas, A.I., 2008, January. EVA: a tool for environmental assessment of novel propulsion cycles. In ASME Turbo Expo 2008: Power for Land, Sea, and Air (pp. 547-556). American Society of Mechanical Engineers Digital Collection.

Liu, Y., Sun, X., Sethi, V., Nalianda, D., Li, Y.G. and Wang, L., 2017. Review of modern low emissions combustion technologies for aero gas turbine engines. Progress in Aerospace Sciences, 94, pp.12-45.

Perullo, C.A., Trawick, D.R. and Mavris, D.N., 2016. Assessment of engine and vehicle performance using integrated hybrid-electric propulsion models. Journal of Propulsion and Power, 32(6), pp.1305-1314.

Pornet C, Kaiser S, Isikveren AT, Hornung M. Integrated fuel-battery hybrid for a narrow-body sized transport aircraft. Aircraft Engineering and Aerospace Technology: An International Journal. 2014 Sep 30.

Pornet, C. and Isikveren, A.T., 2015. Conceptual design of hybrid-electric transport aircraft. Progress in Aerospace Sciences, 79, pp.114-135.

Roskam, J., 1985. Airplane Design: Part 5-Component Weight Estimation. DARcorporation.

Sahoo, S., Zhao, X. and Kyprianidis, K., 2020. A Review of Concepts, Benefits, and Challenges for Future Electrical Propulsion-Based Aircraft. Aerospace, 7(4), p.44.

Sahoo, S., Zhao, X., Kyprianidis, K.G. and Kalfas, A., 2019. Performance Assessment of an Integrated Parallel Hybrid-Electric Propulsion System Aircraft. In ASME Turbo Expo 2019: Turbomachinery Technical Conference and Exposition. American Society of Mechanical Engineers Digital Collection.

Scherer, C., 2019. Global Market Forecast Cities, Airports \& Aircraft 2019-2038.

Sielemann M., Coïc C., Hübel M., Zhao X., Kyprianidis K.G., 2020, Introduction to Multi-Point Design Strategies for Aero Engines. In ASME Turbo Expo 2020: Turbomachinery Technical Conference and Exposition (to appear).

Sobol, I.M., 1993. Sensitivity estimates for nonlinear mathematical models. Mathematical modelling and computational experiments, 1(4), pp.407-414.

Takahashi, T.T., 2015. The Impact of ATTCS on Reduced-Thrust Takeoff Field Performance. In 15th AIAA Aviation Technology, Integration, and Operations Conference (p. 2698).

Torenbeek, E., 2013. Synthesis of subsonic airplane design: an introduction to the preliminary design of subsonic general aviation and transport aircraft, with emphasis on layout, aerodynamic design, propulsion and performance. Springer Science \& Business Media.

Walsh, P.P. and Fletcher, P., 2004. Gas turbine performance. John Wiley \& Sons.

Wroblewski, G.E. and Ansell, P.J., 2019. Mission analysis and emissions for conventional and hybrid-electric commercial transport aircraft. Journal of Aircraft, 56(3), pp.1200-1213.

Zhao, X., Sahoo, S., Kyprianidis, K., Rantzer, J. and Sielemann, M., 2019. Off-design performance analysis of hybridised aircraft gas turbine. The Aeronautical Journal, 123(1270), pp.1999-2018.

Zhao, X., Sahoo, S., Kyprianidis, K., Sumsurooah, S., Valente, G., Rashed, M., Vakil, G., Hill, C.I., Jacob, C., Gobbin, A. and Bardenhagen, A., 2019, June. A framework for optimization of hybrid aircraft. In ASME Turbo Expo 2019: Turbomachinery Technical Conference and Exposition. American Society of Mechanical Engineers Digital Collection. 